\title{
The lucky penny: an illustration of the bullet rule
}

\section{Paul T. Engels MD, Homer C. Tien MD MSc}

A 20-year-old man with no previous history of penetrating trauma sustained multiple gunshot wounds to his torso and left leg.

The patient was hemodynamically stable and received a score of 15 on the Glasgow Coma Scale. His clothing was removed, and he was noted to have six bullet wounds: one in the left upper quadrant, one in the left flank, one suprapubic, one in the midline of the lower back, one in the left lateral thigh and one in the left buttock (Figure 1). All of the wounds were small $(<1 \mathrm{~cm}$ diameter), semicircular skin defects with no substantial associated loss of soft tissue. Further examination showed that the patient had diffuse peritonitis and gross hematuria. His lower limbs were neurovascularly intact, but severe abdominal pain caused him to move them with difficulty. Sonography showed intraperitoneal fluid. Radiographs of his torso and left leg showed two bullets in his left thigh (Figure 2A) and none in his torso. Based on these findings and the patient's recollection of being shot from behind, we believed wound 2 represented the entrance wound of one bullet, wound 1 was the corresponding exit wound, wound 5 was the entrance wound of a second bullet and wound 3 its corresponding exit wound. Because two bullets appeared to be visible on a radiographic image of the patient's left thigh, we surmised that wounds 4 and 6 represented the entrance wounds of two separate bullets.

During a laparotomy, injuries to the patient's bowel and bladder were identified and repaired. The wound to the patient's left thigh was also explored during surgery, as what was thought to be a bullet was palpable superficially. However, this "bullet" was in fact a Canadian penny that had apparently been struck by a bullet and driven into the subcutaneous tissues of the thigh (Figure 2B). The bullet itself was deeper in the thigh and was left in situ.

The "bullet rule" has been previously described $^{1}$ and is used to avoid missing important injuries by better understanding the potential trajectory and location of bullets. ${ }^{1-3}$ The rule states that the sum of the number of bullet wounds and actual bullets seen on diagnostic imaging should always be an even number. Bullets can either traverse the body and leave both entrance and exit wounds, or they can enter and remain in the body. In the latter case, the patient would have one bullet wound and one bullet visible on imaging.

For our patient, finding a penny instead of a bullet led us to look for another in situ bullet, as he now had six bullet wounds and only one bullet evident on imaging (i.e., a sum of 7). Postoperative radiographs located the missing bullet in the soft tissues of the patient's right thigh (Figure 3). Presumably, one bullet entered the patient's left buttock, struck his pelvis and deflected through the soft tissues of his right thigh. Fortunately, there was no associated vascular or bony injury to the patient's right leg.

\section{Discussion}

Patients who sustain gunshot wounds are at risk for serious injuries and often require emergency surgery. ${ }^{3}$ All clothing should be removed and the patient's entire body examined from head to toe to identify all gunshot wounds. Determining the trajectory of bullets is critical in evaluating these patients, as the trajectory can determine the need for surgery and prognosis. For example, selected tangential abdominal gunshot wounds may be managed nonoperatively. ${ }^{4,5}$ Conversely, other trajectories may suggest unfavourable outcomes and the need for surgery to control damage. ${ }^{6}$

Determining the trajectory of a bullet can sometimes be straightforward. Entrance wounds

\section{- KeY POINTS}

- Patients who sustain gunshot wounds must be completely exposed to identify all wounds.

- The sum of the number of bullet wounds and in situ bullets seen on diagnostic imaging should be an even number ("the bullet rule").

- Radiographic investigation should be used to exclude any missed bullets and associated injuries in patients with gunshot wounds that do not satisfy the bullet rule.
Competing interests: None declared.

This article has been peer reviewed.

Correspondence to: Dr. Paul T. Engels, pengels@ualberta.ca

CMAJ 2012. DOI:10.1503 /cmaj.110210 
often have typical signs such as muzzle marks, tattooing and soot. These signs may appear as dark, circular discolourations and punctate stippling on the skin surrounding the wound, created by the deposition of combusted and uncombusted gun powder exiting the barrel of the weapon. In addition, entrance wounds may have inverted, irregular edges with stellate lacerations caused by the injection of gases into the subcutaneous tissue. ${ }^{7}$ Exit wounds generally have everted, irregular edges, usually lack evidence of soot and tattooing and are often larger than entrance wounds. ${ }^{7}$ Furthermore, most bullets that enter the body travel in a straight line., ${ }^{2,3}$ Thus, determining a bullet's trajectory often only requires identifying the entrance and exit wounds and determining the straight line between the two points.

Substantial pitfalls exist, however, with applying this simple method. Although entrance and exit wounds can have typical appearances, this determination is not always clear in the acute setting, and misinterpretation may hinder criminal

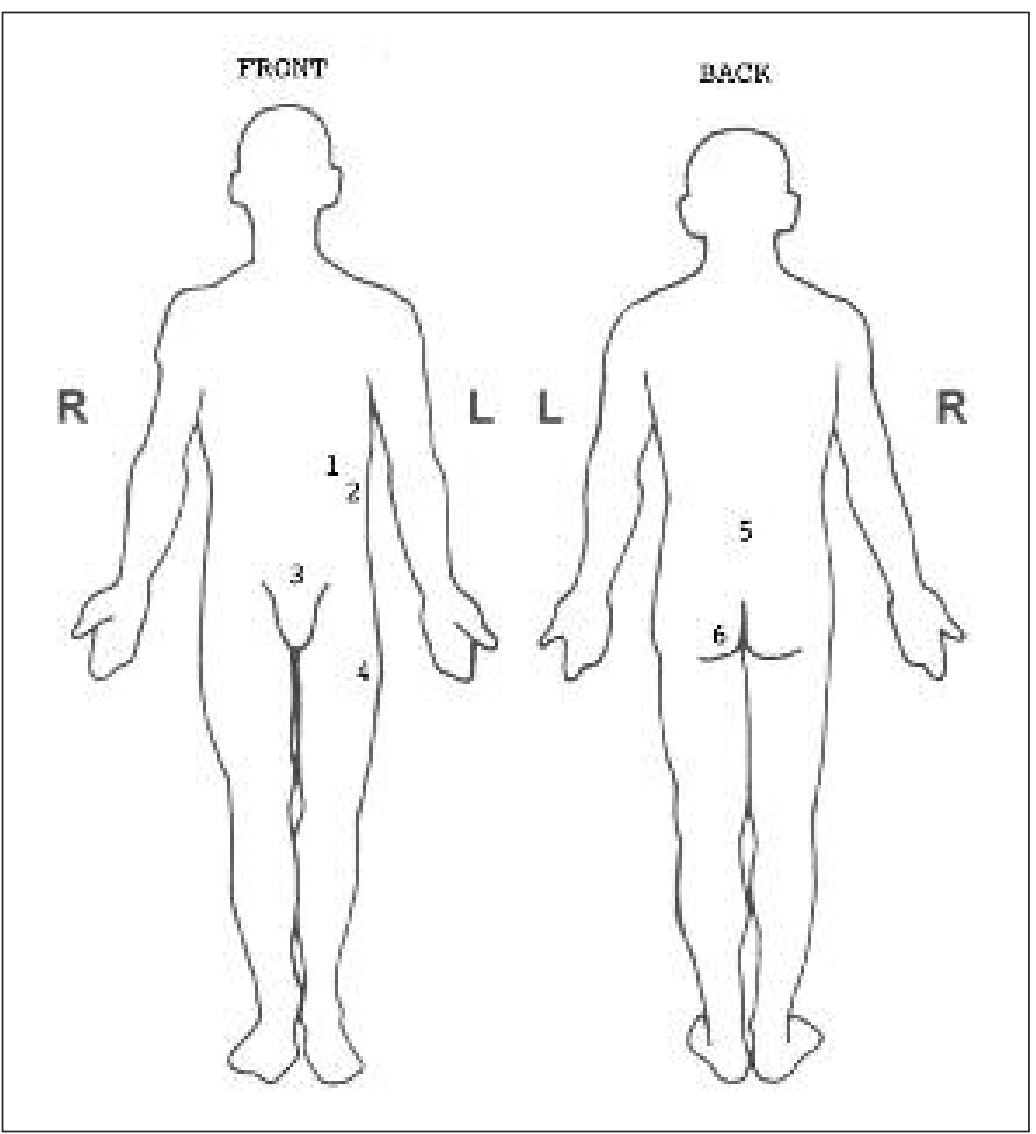

Figure 1: Diagram showing gunshot wounds (numbered 1-6) sustained by a 20year-old man with no previous history of penetrating trauma. The likely bullet trajectories were wounds 2 and 1, representing a single on a through-andthrough course, wounds 5 and 3 , representing a second single bullet on a through-and-through course, and wounds 4 (bullet lodged in left thigh) and 6 (bullet lodged in right thigh), corresponding to entrance wounds where bullets remained in the body. and legal investigations..$^{8-10}$ One such example is the forensic controversy that arose after the assassination of John F. Kennedy. The frontal wound in Kennedy's neck was originally described by the attending emergency physician as being an entrance wound, thereby contributing to the confusion over the number of shots fired and the possibility of a second shooter. However, the trauma surgeons involved later testified that the wound in front of the throat could have been either an entrance or exit wound. ${ }^{11}$ As such, current forensic recommendations are that trauma clinicians not document the interpretation of wounds as "entrance" or "exit." The wound should only be described in detail and, if possible, photographed. ${ }^{7,9}$

Another pitfall in determining trajectory is the so-called "wandering bullet." One reason for this phenomenon is deflection. Bullets that
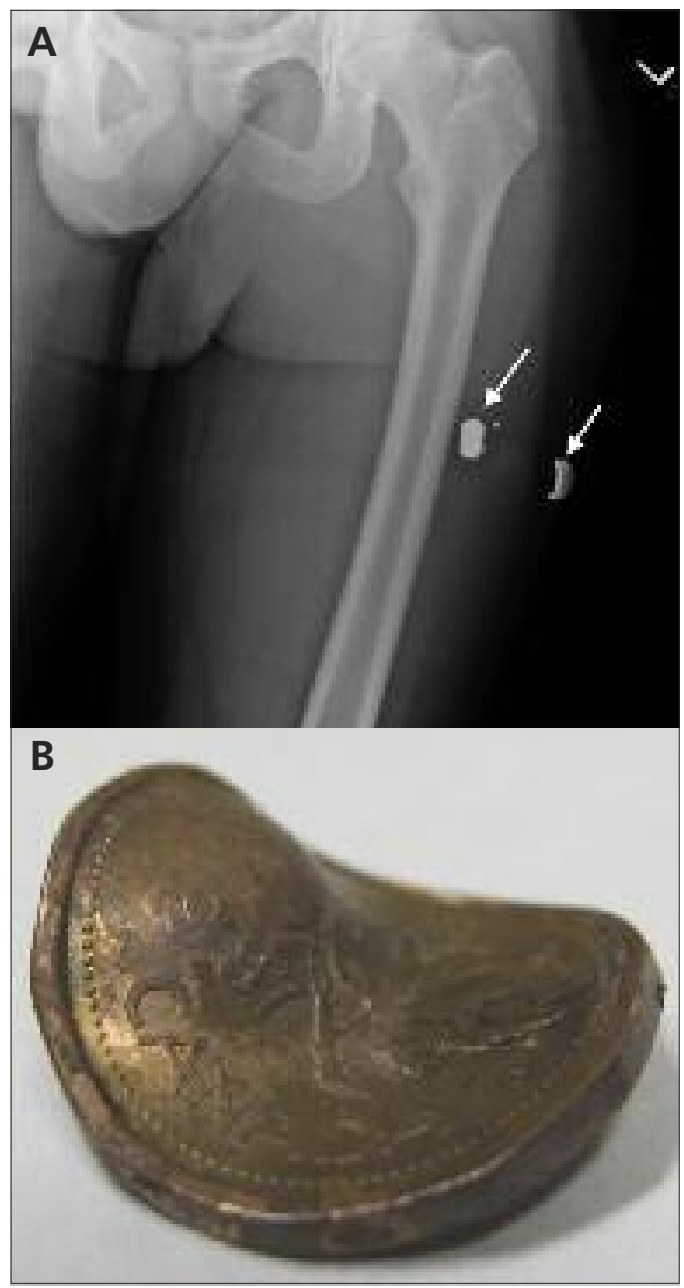

Figure 2: (A) Radiographic image showing two objects, both thought to be bullets (arrows), in the left thigh of a 20-year-old man with multiple gunshot wounds. (B) The lateral object removed from the patient's thigh was actually a Canadian penny that had been driven into his thigh by the medial bullet (B). 
strike rigid changes in density, such as bone, will often be deflected from their initial course. ${ }^{12}$ Another explanation for a change in trajectory is bullet embolization, first reported by Schmidt in 1885 as described by Smalls and Siram. ${ }^{13}$ In that account, the bullet had penetrated the chest, entered the left pulmonary vein and embolized to the left femoral artery. Since that first description, numerous other authors have reported their experiences with bullet embolization. ${ }^{14,15}$

The experience of our patient highlights the clinical importance of the bullet rule in helping to determine the trajectory of the wandering bullet and avoiding missed injuries. Accounting for all bullets and all bullet wounds allows for a basic reconstruction of each bullet's trajectory, thus identifying organs and tissues at risk of damage. If the sum of bullet wounds and in situ bullets is not an even number, further diagnostic imaging is necessary to locate the missing bullet.

\section{Limitations of the bullet rule}

Although the bullet rule is a helpful concept, the term "rule" suggests possibly more strength of evidence than actually exists. There are well-documented exceptions to the bullet rule. One example is two bullets fired in unison as tandem bullets from a handgun entering the body through the same entrance wound, but leaving two bullets in situ; ${ }^{16}$ another example is a bullet that ricochets within the calvarium, entering and exiting from the same point. ${ }^{17}$ Therefore, the real purpose of the bullet rule is

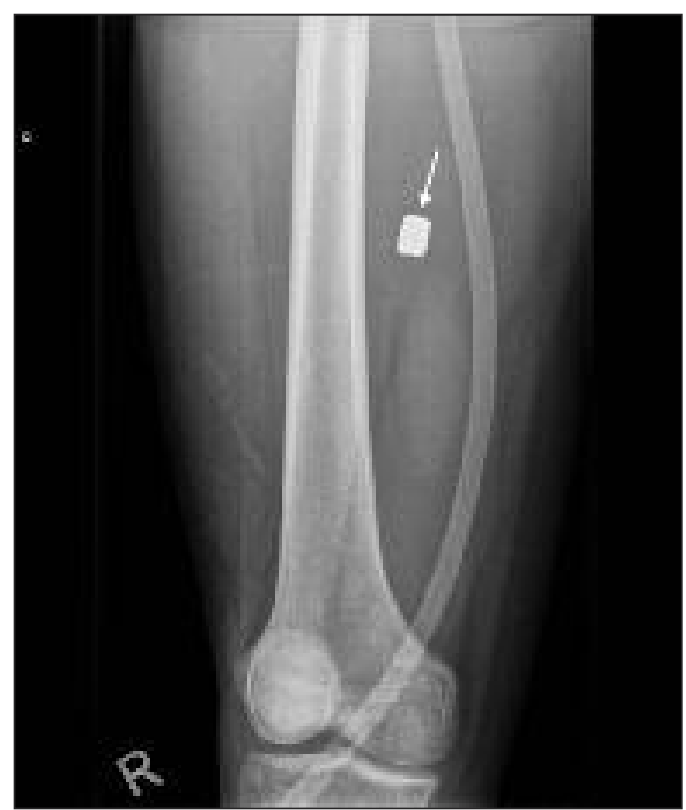

Figure 3: Radiograph of the patient's right thigh showing the "missing bullet" (arrow). to remind clinicians to look for additional injuries and to be diligent in the evaluation of patients who have suffered gunshot wounds.

\section{References}

1. Westreich M. The odd or even bullet. Injury 1986;17:45-6

2. Ledgerwood AM. The wandering bullet. Surg Clin North Am 1977;57:97-109.

3. Feliciano DV, Mattox KM, Moore EE. Trauma. 6th ed. New York (NY): McGraw-Hill Professional; 2007.

4. Grossman MD, May AK, Schwab CW, et al. Determining anatomic injury with computed tomography in selected torso gunshot wounds. J Trauma 1998;45:446-56.

5. Demetriades D, Velmahos G, Cornwell E, et al. Selective nonoperative management of gunshot wounds of the anterior abdomen. Arch Surg 1997;132:178-83.

6. Hirshberg A, Wall MJ, Mattox KL. Bullet trajectory predicts the need for damage control: an artificial neural network model. $J$ Trauma 2002;52:852-8.

7. Olshaker JS, Jackson MC, Smock WS. Forensic emergency medicine. Philadelphia (PA): Lippincott Williams \& Wilkins; 2001.

8. Randall T. Clinicians' forensic interpretations of fatal gunshot wounds often miss the mark. JAMA 1993;269:2058, 2061.

9. Fackler ML. How to describe bullet holes. Ann Emerg Med 1994;23:386-7.

10. Denton JS, Segovia A, Filkins JA. Practical pathology of gunshot wounds. Arch Pathol Lab Med 2006;130:1283-9.

11. The Warren Commission. Chapter 3: The shots from the Texas School Book Depository. In: Report of the President's Commission on the Assassination of President Kennedy. College Park (MD): National Archives. p. 89. Available: www.archives.gov /research/jfk/warren-commission-report/chapter-3.html (accessed 2011 Apr. 14).

12. Peitzman $\mathrm{AB}$, Rhodes $\mathrm{M}$, Schwab $\mathrm{CW}$,et al. The trauma manual: trauma and acute care surgery. 3rd ed. Philadelphia (PA): Lippincott Williams \& Wilkins; 2008. p. 18.

13. Smalls NM, Siram SM. The wandering bullet. J Natl Med Assoc 1988;80:678-9, 682.

14. Burihan E, Pepe EV, Miranda F. Bullet embolism following gunshot wound of the chest: Case report and review of the literature. J Cardiovasc Surg (Torino) 1980;21:711-6.

15. Nguyen R, Ouedraogo A, Deneuville M. Gunshot wounds to the chest with arterial bullet embolization. Ann Vasc Surg 2006;120: 780-3.

16. Bentley AJ, Busuttil A, Clifton B, et al. Homicidal tandem bullet wound of the chest. Am J Forensic Med Pathol 1997;18:56-9.

17. Grey TC. The incredible bouncing bullet: projectile exit through the entrance wound. J Forensic Sci 1993;38:1222-6.

Affiliations: From the Department of Surgery (Engels), Sunnybrook Health Sciences Centre and the University of Toronto (Engels, Tien), Toronto, Ont.; and the Canadian Forces Health Services (Tien), Department of National Defence, Ottawa, Ont.

Contributors: Both authors have contributed to and have approved the final manuscript. This work has not been previously published and is not under consideration for publication elsewhere. The authors have no professional or financial conflicts of interest that would influence the conduct or reporting of the manuscript.

Acknowledgement: The authors acknowledge the efforts of Dr. Bryan Wells in recovering the "lucky penny" from this patient.

$C M A J$ remains committed to notifying readers in a timely way about advisories and warnings pertaining to serious adverse drug events. A collection of recent drug advisories from Health Canada and the US Food and Drug Administration is regularly updated at www.cmaj.ca/misc /advisories.xhtml. 